\title{
The Socio-Psychological Impact of Divorce on School Children through Analysis of Interviews Implemented to Students and School Psychologists in TiranalAlbania
}

\author{
Muhammed Ali Isik \\ European University of Tirana, Tirana/Albania \\ muhammedali77@hotmail.com
}

\begin{abstract}
Recent studies indicate that there is great influence of divorce on children's lives. The effect of a divorced couple with children may cause a lifespan impact on them; especially young aged children may experience dramatic and traumatic adjustments that could lead to mental, physical and emotional disorders. The effect is not only with visible traces but also their mindsets, hearts, spiritual well-beings may get effected from low to high scales; visible to non-visible; longterm to short term periods. The present study was mainly focused on divorced children from secondary and high school students in Albania as to observe, investigate and analyze the impact of divorce on children and their school lives. One of the main problems observed with divorced families was the uncertain role of the parent that would beheld child's educational needs. Also how divorce impact on those children when their parents get the divorced, do they feel secure or not, or do they miss the parents who do not live with children or do they hate them. Do those children have low academic achievement in school, or not were main concerns of the present study. Together with this particular study as well as the interview with some psychologists, the obtained data and analysis of them indicated that support from school does not provide sufficient emotional support for children of divorced families. Present study also shows that there isn't significant correlation between psychologists, children and parents in regard with expected sufficient emotional support and betterment of children's current situations.
\end{abstract}

Keywords: Divorced children, emotional support, role of the parents, school life, school psychologists.

\section{INTRODUCTION}

It's one of the commonly accepted facts that family norms, concepts of relationships, different ways of experiencing life, values of individuals together with society, policies for family plans and structures have gone through big changes within last decades. Although the change seems to be continues, including some laws in relation with divorce, the changes were unfortunately indicate negative side effects for children of divorced families as divorce together with new laws became easier for couples which increased the number of divorced parents. Other many studies conducted on divorce in eastern countries also show that the rate has been higher since a couple of decades (Hetherington \& Stanley-Hagan, 1999). The present study in regard with literature written on the issue aims at investigating the roles of divorced parents on education of children, their impact on their socializations etc.

At this point, it is worth to mention that one of the primary concern of the study was also to observe those children 's lives at school, at home, and within society by interviewing them andlor their immediate related people around them. Questions like; how were they being transformed from family life to divorced couples life, how did they behave differently in those situations, what happened to their identities as in their perception of themselves or others' perception of them. The social life has significant role on divorced children; being part of the society, creating social belonging and identity, developing their own ideas, preparing their future to share experiences with friends at the same time.

The overall aim of this research was to find the influence of education that parents have and how it influences on children's academic achievement. Do they comprehend the feelings of the children while taking the decision of divorce? I also chose to study and know more about these children if they had financial issues and if they received any social support from governmental entities. Some phrases were also taken from some students as to conceptualize their thought about divorce and how did they perceive the divorce of the parents. The structure of the survey implemented was created as to have a 
more clear idea of divorce as a phenomenon and the effect of divorce on those children. Were children supposed to choose the alternative or the best choice for them? Were they able to make rational choices at that point?

According to majority of studies children with divorced parents indicate a higher level of anti-social behavior and difficulties in pair-work and school tasks in comparison with children of whose parents were not divorced, (Najmanet et. al, 1997). Studies of the implications of parental separation for children's well-being have consistently shown that children of divorced parents fare worse on different measures of well-being than children living in intact families (Amato, 2001; Amato and Keith 1991). On the other hand, it's worth to mention that there is solid evidence that divorce has negative impact on children in short term, however, there is not sufficient study investigating the impact on long-term periods and its relation with socioeconomic outcomes.

Another fact is that children of divorced parents are those that have problems at school as well. They don't study well, they have low school performance, they get aggressive with other children, and, also they may go through depression because of their parents' mistakes on not caring enough for them. These children prefer to be alone, they are mostly anti-social because of their low self-esteem, and also their behaviors are very disrespectful. Since they live in Albania, those children are more adapted with Albanian way of thinking, values, norms, ways of behavior and they feel forced to act according to the expectations of the society they live in. Socialization in this regard is one of the most important elements of the Albanian society for those children.

\section{METHODOLOGY}

The methodology used on this scientific paper was qualitative. Qualitative methoid is the method that did not get results with statistics but interpreted questions which puts this study into a qualitave form. Sstudents from divorced families, aged from 11 to 18, and also psychologists of some schools, in Tirana, were interviewed about the psychological impact of divorce and the status of social support in their lives. The interview for school psychologists was implemented by the usage of the same interview for divorced parents and they were asked of their thoughts on those children. Psychologist mostly mentioned that children were the fruit of their parents and that they were influenced by them as well as in applying some changes on themselves; as they felt like acting according to the behavior of their parents during divorce and after it.

Advantages of using a qualitative method to a school psychologist were to collect data for divorced parents and their children and by observation in their lives. It was aimed to see the everyday problems of children which they had every day in their family and in school, in society also they were prejudiced by some friends and others as well. How do they perceive this and how do they pass this within themselves?

\section{THE SOCIO-PSYCHOLOGICAL IMPACT OF DIVORCE ON CHILDREN}

The literature written on divorced children in secondary and high schools in Tirana shows the positive and negative; advantages and disadvantages for those children during school. The common issues which contains with the important role of parents on children education. Also how the divorce indicate in those children when their parents get divorced, do they feel secure or not? Are they missing the parents who do not live with children or do they hate them? "Furthermore, considering the fact that the law on divorce has changed, divorce can be carried out easier and quicker. Due to this big change the number of divorces has increased". (Hetherington \& Stanley-Hagan, 1999) The process of divorce is widespread in Tirana. Many studies show that the divorce rate is quite high in many Eastern countries. But the mentality of the divorce in Albania hasn't become as it is in Europe, because the family lost the respect of the society and they prejudice them. So, those families keep inside just not to prejudice others. While other studies compare the behavior of children with divorced parents and children whose parents are not divorced, this study was focused on behavior problems and emotional disorders in children with divorced parents reported by children themselves who are compared to the data reported by their teachers, psychologists and their parents. "Patterns of family interaction and behaviors pertaining to roles in the family remain consistent and stable over time" (Whitbeck, Hoyt, \& Huck, 1994) This means that many of the problems that a child experiences due to poor physical or emotional relations with their parents will remain a part of their lives into adulthood.

Paternal relations and attachment is an area of research that has been neglected and needs to be investigated further since attachment to the father can be viewed as a protective factor for many externalizing behaviors. Adults who perceived a greater deal of fatherly affirmations in the past have an increase in their self-esteem and can decrease their fear of intimacy. This can be seen in both men and women (Naus \& Theis, 1994; Scheffler \& Naus, 1999).When an individual 
experiences a conflicted relationship with their father they are at risk for experiencing problems in adolescence through adulthood.

The relationship with the father can have a very significant impact on both sons and daughters; however, this impact may vary between girls and boys. At one point most research supported a greater link of the mother child relationship to attachment of children however more recent research has shown that the link between father child relations and attachment is much stronger (Lamb, 2004). As observed throughout the reviewed literature there hasn't been a significant research on divorced children in secondary and high school which is one of the main objectives of this study as to provide data and results in understanding the level of those divorced children at schools in Albania.

\section{PSYCHOLOGISTS` RESPONSES TO INTERVIEW QUESTIONS}

As one of the purposes of this study was to investigate the relationship between social support from the state and its psychological impact on children; the influence of positive and negative effects on divorvced children that come from social impact in school and family was taken into consideretion as well. This chapter included data analysis that are taken on interviw realise by psychologists and students in schools Tirana. In this research had been applying an interview with 13 questions in different school psychologists in Tirana, There was 10 psychologists and 10 students who want to share their feeling about their family divorce. Questions are made to prove the hypothesis that the state does not protect the social life of divorced children in nursing homes.

\subsection{Do you agree that divorce has effect on children?}

- Obviously that affects, for two of the most important figures for the child's life would suddenly put the child in a difficult position of selection, and whether the parents will have real conflicts, one that will pay more the child will be.

In first question the all Psychologists said that the divorce effect on children life, behavior, and they have the difficulty in beginning new life without one parent. Here they agree with question.

\subsection{Does divorce have an effect on children`s behaviour?}

- In most cases parents during divorce have less time, attention and commitment to the child. Also parents change their attitude towards this without discussion to bother children. Exactly when the child requires more attention than ever, they do not have and not only feel hurt by this story, but their condition aggravated different emotional consequences without compromising here and the emergence of depressive signs.

In second question, Psychologists accepted that the divorce reflect in children behavior, their parents change their attitude towards this without discussion to bother children. This time is when the children needs more attention than ever, and they parents get the divorce and this make children feels loss from them or they feel faulty in front of parents because they thing that because of them they get divorce.

\subsection{Have you encountered any of such cases?}

- No, I have not known.

- Emotional reactions are different children and basic adult or family where they belong. There are cases when the custodial parent after divorce does not allow the child to meet with the other parent or the child has been tried to reconcile the parents organizing something in secret (ex. Meeting), not only has failed to reconcile, but He received as a "reward" insults and showed aggressiveness parent to child.

- Extreme cases are those cases where children in a small age, not only as they create the possibility of meeting with parents who live apart, but was denied his existence, saying that Mom or Dad is dead even although the child is aware that there are living parent.

- In these instances, the child appeared unable panic, confusion, becomes hostile, keeps itself guilt, mental and physical fatigue also appeared rejection in most cases. But without bypass and when the child prefers to remain silent suffering itself. 
In third question, Psychologists discuss for children reaction that they pass after a divorce. Some of those children show panic condition, confusion, become hostile, keeps itself guilt, mental and physical fatigue also appeared rejection in most cases thought psychologists in the interview.

\subsection{Is there a relation between divorce and healthy psychological growth of a child?}

- Due to all the changes involved in divorce, parents may become impatient, irritable, and less emotionally and physically accessible to their Children. Both a result, children may be angry and stressed by the divorce and the changes associated with it. Furthermore, may children act out by showing their anger and pain. While he is away either by images of parenting, of course it growth will exceed new challenges.

In the fourth question, psychologists analyzed the effect of divorced children, and they analyses the causes of children psychologically health. Here psychologists mention the problems that a child could have from the divorce.

\subsection{What are the difficulties of divorce and how can children overcome with consequences?}

- Parents' Divorce leaves traces in the life of every child. (This does not exclude the geniuses). Goethe said: "No one should believe that can save the impressions of his youth." The consequences are different depending on family dynamics, emotional balance of the parents, professional support offered by schools and society. The consequences are behaviors with peers, performance in lessons, increase aggressiveness or the opposite conclusion in itself as it increases feelings of guilt in relation to divorce. Child suspects or believes that he was the cause of separation of the parents, and the child did this action will close by itself, will become antisocial because guilt that he has in himself will accompany lifetime.

In fifth question, Psychologists mention the causes of consequences of a child during parental divorce. Parents should look for the future of their children not just for the moment and this thing just few parents do because their consequences are different depending on family system, emotional balance of parents, professional support offered by schools and society.

\subsection{Which gender groups are more affected? Boys or Girls?}

- No genuine study in Albania first to determine.

In sixth questions, two of psychologists does not give an answer because they don't have any genuine study in this aspect, they don't have real statistic in this question.

- It is found boys that were more affected after the divorce, whereas girls were found to experience more disturbances before the divorce. Parents children whose-ended in divorce displayed ultimately poorer and more emotional adjustment problems prior to the divorce than whose children parents did not divorce.

In sixth question, five psychologists said that boys were more affected after the divorce than girls. They said that boy feels this aspect more difficulty because they will see themselves in father position and they don't wont to do the same as their father did.

- In my opinion, the girls has more difficult because their nature of instinctively is more closed with parents.

Here three of ten psychologists think differently, they thought that girls are more affected in the parent divorce because the girls are more sensitive than boys, also they are more related with parent and they have difficulty to perceive the divorce between two parents.

\subsection{Do children show the effects of divorce on their faces?}

- The very difficult because the structure of personality and temperament more introvert and isolate the child. This isolation makes it the silent within you and suffers the separation of parents thinking that they are behind the separation of his parents.

In seventh question, psychologists had the same opinion and they argued that those children has more difficulty than other children because those children don't share anything but they keep everything inside of themselves, and his thing destroy them slowly. 


\subsection{How much of children's pain do parents comprehend?}

- It depends on the educational and cultural level of each parent.

In eight questions, psychologists give this answer, and actually are true because here in Albania most of the parents don't have any education and this make the children feel bad because they don't understand their children, they leave children there and just go ahead for her new future, but they forget that her new future is her child.

\subsection{Is there anything positive about divorce?}

- Yes. In cases where the report in pairs is tense and more violent it is healthy for the couple to split, so that the child is not to create scenes with themes such cognitive.

In nine questions, one psychologist argue in this way, because in the family the rapport of the parents is tense and violent, for children is healthy that their parents to get the divorce.

- Yes. Even though divorce can bring temporary stress to the family, we may also provide a second chance for happiness for parents. Children tend to benefit from the divorce in cases where there is a high-conflict marriage. It is argued that the positive outcomes.

The most psychologists that I conclude from the interview said that the divorce can bring stress to the family, so if those parents won't to stop the stress in the family, they provide for e new chance for happiness for their family.

- No, because some children have a good memory and they remember the scene of their parents during the divorce. Some of those children will repeat the behavior that their parents have done, and they get divorce too.

Here two psychologists does not accepted the new chance for a good family because they thing that some children has such a good memory and they remember the scenes of the violence in the family and if those scenes will repeat again they will do the same thing in their future, because children do what they see and what they learn, says psychologists.

\subsection{How much time does it take for a child to adapt the divorce?}

- It depends on the way the parents are divided and how the child has experienced divorce. There are children who spend quickly sharing parents who do not want to know what they do, there are children who feel guilty about the separation of parents, also have children who feel lonely after the departure of one of the parents.

In the ten questions, psychologists argued in this way, because there is no fixed time for each child to adapt in divorce. All children are differing from each other and their personality change too, some of them adapt with divorce easy and some of them can't accept the divorce as a phenomenon.

\subsection{What are some elements that impact the adaptation process?}

- Positive social network, relatives, schools and obviously is supported psychological. If the child is a teenager, he did not blend between separations of the parents. But it depends on you from every child resurges and social impact of resurges.

In question eleven, psychologists mention some factors for the children adaption, the most answer of the psychologists were positive because the factors are showed in our life such as family support, social networks, psychological support, etc.

\subsection{Do children learn to adapt or does it happen itself?}

- It depends on internal resurges having each child and social resurges. It depends on each child how he sees it and how tends a child to adapt to a new life. Not every child fits easily with divorcing parents.

In question twelve, psychologists say that the divorce depends on internal resurges, and how a child can adapt with the divorce. There is not a fixed if a child can adapt easy or not with divorce. 


\subsection{What do children need to know about divorce?}

- The child talk about the causes why parents are separated (as understood as a child should know) explained both by parents and by a psychologist.

- Initially, the child should be noted that the issue of divorce, why it happens and what are its causes. The child talk about the causes why parents are separated (as understood as a child should know) explained both by parents and by family or school psychologist.

And in the last questions, psychologists mention some facts that a child should know about the divorce, they mention also that they should learn as much as they can perceive not to learn new things that they don't or can't perceive.

\section{STUDENTS` RESPONSES TO INTERVIEW QUESTIONS}

Divorce has a negative impact, not only to parents (the couple), but also to their children. Teenagers who have experienced parental separation in this period are more susceptible. They are at an age to understand the consequences of separation. They are adults and feel offended before their peers. They talked about their parents superlatives, and now do not know what to say. They are at the age that need more advice, suggestions and support of both parents, and now the man was missing. In this category of students prevailing sadness, melancholy, sadness, uncertainty about life, pessimism.

- "Why my poem was so sad, but why my heart sings pain, why my life is so fragile, why my eye often often kilotons." (L., third year student).

- $\quad$ "Fly in fever, stuck here in my silence. I have within me the s'dal out of it. I remained so, oh of how long ". (S., student of first year).

Councils of both parents, their constant support, their unceasing care of more teenagers Grill, makes them more resistant and better able to overcome the difficulties of the age of life. When it is partial, their mood deteriorates.

- "Well, death, come get me, I am waiting for you! Hearing or disobey?! ... I'm better with you that damn wicked life. Often I would rather die than to live. "(J.., Third year student).

Someone, son even calls the death, they are dissatisfied, not just with themselves, with their fate, but also the people around them, the reality in which they live. In the end their revolt directed against opinion bystander (also seek his help).

- "Oh, people get! Do not understand that are killing themselves, they are the living die! "

Their accusation is heavy, ruthless. Solution: another world, a true black, a new faith to give another meaning to their life.

- "I want to drink, to carouse, to be a stopper, to forget reality, you lose the sense of pain, to invent another world". (l., third year student).

Adolescent whose parents are divorced is always tense. There is confidence in ourselves and always worried that doing wrong. Even when everything goes well he worries about the future and therefore is difficult to soothe themselves. A significant source of stress among adolescents is concern secondary post-traumatic loss or separation from a parent. They express themselves and their spiritual state, in short, very touching and meaningful.

- "Words: One, sorrow, sadness suit my state of mind ... Often able unscrupulous!!! ... I continue to roam held to silence. I remain to be a sick feeling, broken thoughts ". (J., student of fourth year).

- "I curse ... I am nobody."

As seen this age, especially 17-18-year-olds read Freud, Nietzsche and affected. (Impact on the negative side is greater, according to this category of teenagers, whose parents are divorced). Being seen in their works find themselves. It is therefore necessary to plan and organize conversations discussions of Freud's theories of Nietzsche, the invited scientists and psychologists old to understand the essence of them. Disappointed by their parents who seemed angels, but was not really went well, their hatred for yeast to multiply without limit. 
- "The most beloved faces become hostile, even sweeter smile becomes sickening and disgusting grimace." (L., third year student).

- "The best ...!!! Who can determine the extent of human kindness?! "(A., student of fourth year).

This affects the objective assessment of itself and makes indifferent, inferior in communications and relations with others, especially with their friends. People marry because "they like", because "in love" and stay together while continuing to delight, while still called lovers. Their separation, divorce of a couple does not mean that they are bad. They were divided than not loved each other, or have projects completely different from each other, but did not know before marriage or after marriage were born. A relationship cannot be established on weakness ... human relations require determination, commitment, responsibility. A couple even though there may be problems refuses to stay together for the sake of children, for economic reasons, the public fear, stick together to have no where to hold, they do not trust one another about the best, they have fear adventures. But when love is absent to the couple, it is better to split.

- $\quad$ "That morning I was in a great anxiety. In the courtroom watching the faces of my mother and father. They were concerned that with any sister and I go. When the court decided that we would be with my mother, my heart broke because I thought I would not stay with his father and will not pass those beautiful moments I spent with my parents, I would have no more warmth my father, I would not be on his defense, nor his caresses. - Every Saturday out with my father and when I get bored I am. " (S., student of first year).

Separation of parents, especially adult children leave an indelible impression. They describe the deep pain the moment. To experience the breaking of your parents' marriage may be one of the most painful things that can be imagined.

\section{CONCLUSION}

As the conclusion a short summary about all this research for divorced parents and for the effect of the children would be necessary. The interview that was done with psychologists was from the high schools in Albania, Tirana. Most of the children who had the family divorced had low school performance at school; they did not have a social protection from the state to have a good life and a protective life as other students. Many of those children had behavioral problems such as aggressiveness, antisocial behavior, emotional and cognitive problems. If we analyze those children in psychologist's aspect, they show low academic achievement, they don't want to go to school, they could easily be addicted with substances, and they didn't have parental control, which was the most needed for their age. If we take to analyze the phrases of some students who accepted to write about the divorce, they show high depression and low self-esteem for themselves, they said that they wanted to die and not to see the situation of their parents' divorce. They wrote down also for the violence in the family between the parents, how their fathers treated them because he was alcoholic, and another child wrote down for the way of communication with the family which concluded with divorce. Most of the children called for death to take them, here the depression was very high and the pessimism was shown everywhere. Those children unfortunately needed support from their psychologists or their teacher at least, because their parents wouldn't provide. To take the aspect of the parents they didn't care for their children because of their own problems, firstly they wanted to solve their problems than later to take care of their children but they were forgetting that the real victim of the divorce were their children. Most of the parents didn't have high level of education and this thing made them not to understand their situation, emotion, and their progress at school. Most of the time they left their children free and didn't care for them. In the interview it was observed that from the answers of psychologists that those children had a lot of problems but there was no governmental entity to protect them and to help them financially and to find a new place safe to live in. Those children also had mental problems because of their neighbors, peers and their friends as they felt to be prejudiced by them.

\subsection{Recommendations for Enhancement of the Current Situation}

It could be suggested that for those children, the state should provide a family psychologist for each family, because a family psychologist would help them to solve the problem and not to bring the divorce in their family.

Each school should have its own psychologist who can help those children to pass the depression and feel same as other children at school; a school psychologist also could help them to have high school performance at school. 
Also, the state should have some centers where those families could find treatment there after divorce and there also should be a psychologist to give them trainings for divorce and how to pass it; what to do after divorce; and how to start a new life.

\section{REFERENCES}

[1] Amato, P. R. (2001). Children of divorce in the 1990s: an update of the Amato and Keith (1991) metaanalysis. Journal of family psychology, 15(3), 355.

[2] Amato, P. R., \& Keith, B. (1991). Parental divorce and the well-being of children: a meta-analysis. Psychological bulletin, 110(1), 26.

[3] Lamb, M. E. (Ed.). (2004). The role of the father in child development. John Wiley \& Sons.

[4] Hetherington, E. M., \& Stanley-Hagan, M. (1999). The adjustment of children with divorced parents: A risk and resiliency perspective. Journal of child psychology and psychiatry, 40(01), 129-140.

[5] Naus, P. J., \& Theis, J. P. (1994). THE RELATIONSHIP BETWEEN FATHERLY AFFIRMATION AND A MAN'S SELF-ESTEEM AND FEAR OF INTIMACY: A PRELIMINARY EXAMINATION IN TWO CULTURAL CONTEXTS, CANADA AND THE NETHERLANDS. Canadian Journal of Human Sexuality, 3(4).

[6] Najman, J. M., Behrens, B. C., Andersen, M., Bor, W., O'CALLAGHAN, M. I. C. H. A. E. L., \& Williams, G. M. (1997). Impact of family type and family quality on child behavior problems: A longitudinal study. Journal of the American Academy of Child \& Adolescent Psychiatry, 36(10), 1357-1365.

[7] Scheffler, T. S., \& Naus, P. J. (1999). The relationship between fatherly affirmation and a woman's self-esteem, fear of intimacy, comfort with womanhood and comfort with sexuality. The Canadian Journal of Human Sexuality, 8(1), 39.

[8] Whitbeck, L., Hoyt, D. R., \& Huck, S. M. (1994). Early family relationships, intergenerational solidarity, and support provided to parents by their adult children. Journal of Gerontology, 49(2), S85-S94. 